Canadian

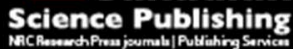

Applied Physiology, Nutrition, and Metabolism Physiologie appliquée, nutrition et métabolisme

\title{
Long Term Effects of Daily Postprandial Physical Activity on Blood Glucose: A Randomized Controlled Trial
}

\begin{tabular}{|r|l|}
\hline Journal: & Applied Physiology, Nutrition, and Metabolism \\
\hline Manuscript ID & apnm-2016-0467.R2 \\
\hline Manuscript Type: & Article \\
\hline Complete List of Authors: & $\begin{array}{l}\text { Nygaard, Håvard; Lillehammer University College } \\
\text { Grindaker, Eirik; Lillehammer University College, Section for Sports Science } \\
\text { Rønnestad, Bent; Lillehammer University College, Section for Sports } \\
\text { Science } \\
\text { Holmboe-Ottesen, Gerd; University of Oslo, Section of Preventive Medicine } \\
\text { and Epidemiology } \\
\text { Høstmark, Arne Torbjørn; University of Oslo, Section of Preventive } \\
\text { Medicine and Epidemiology, }\end{array}$ \\
\hline Keyword: & $\begin{array}{l}\text { exercise < exercise, blood glucose, postprandial, hyperglycemia, } \\
\text { carbohydrate }\end{array}$ \\
\hline \multicolumn{2}{|c}{} \\
\hline
\end{tabular}




\section{Long Term Effects of Daily Postprandial Physical Activity on Blood Glucose: A Randomized Controlled Trial}

Håvard Nygaard, Eirik Grindaker, Bent Ronny Rønnestad, Gerd Holmboe-Ottesen, Arne Torbjørn Høstmark

Corresponding author: Håvard Nygaard, Department of Sport Science, Lillehammer University College, PB 9522604 Lillehammer Norway, tlf: 004761288192, fax:

004761288200, email: havard.nygaard@hil.no

Eirik Grindaker, Department of Sport Science, Lillehammer University College, PB 9522604 Lillehammer Norway, email: eirik.grindaker@hil.no

Bent Ronny Rønnestad, Department of Sport Science, Lillehammer University College, PB 9522604 Lillehammer Norway, email: bent.ronnestad@hil.no

Gerd Holmboe-Ottesen, Institute of Health and Society, Department of Community Medicine, University of Oslo, Norway, email: gerd.holmboe-ottesen@medisin.uio.no

Arne Torbjørn Høstmark, Institute of Health and Society, Department of Community Medicine, University of Oslo, Norway, email: a.t.hostmark@medisin.uio.no 


\section{Abstract}

Previous studies have shown that a bout of moderate or light postprandial physical activity effectively blunts the postprandial increase in blood glucose. The objective of this study was to test whether regular light postprandial physical activity can improve glycemia in persons with hyperglycemia or with high risk of hyperglycemia.

We randomized 56 participants to an intervention or a control group. They were diagnosed as hyperglycemic, not using anti-diabetics or categorized as high-risk individuals for type 2 diabetes. The intervention group was instructed to undertake minimum 30 minutes of daily light physical activity, starting maximum 30 minutes after a meal, in addition to their usual physical activity for 12 weeks. The control group remained with usual lifestyle. Blood samples were taken pre and post.

40 participants completed the study and are included in the results. Self-reported increase in daily physical activity from before to within the study period was higher in the intervention group compared to control ( $41 \pm 25$ vs. $2 \pm 16 \mathrm{~min}, \mathrm{p}<0.001)$. Activity diaries and accelerometer recordings supported this observation. The activity in the intervention group started earlier after the last meal compared to control $(30 \pm 13$ vs. $100 \pm 57 \mathrm{~min}, \mathrm{p}=0.001)$. There were no within or between group differences in any glycemic variable from pre to post test.

In conclusion, the present study does not seem to support the notion that regular light postprandial physical activity improves blood glucose in the long term in persons with hyperglycemia or with high risk of hyperglycemia. 


\section{Keywords}

Exercise, physical activity, walking, blood glucose, postprandial, hyperglycemia, glycemic, carbohydrate, lifestyle.

\section{Introduction}

The prevalence of diabetes is increasing, and is expected to exceed 600 million people before 2040 (IDF 2015). This "epidemic" of diabetes and its co-morbid conditions can be reduced by a healthy lifestyle. It is therefore a need to develop simple and effective strategies for diabetes prevention and treatment, which can be implemented in everyday living.

Postprandial glycemia is the blood glucose level in the absorptive phase after food ingestion. Several studies have shown a strong relationship between the magnitude of postprandial glycemia and cardiovascular disease (Cavalot et al. 2011; Cavalot et al. 2006; Chiasson et al. 2003; Coutinho et al. 1999; DECODE 1999; DECODE 2001; DECODE 2003; Hanefeld et al. 2004; Nakagami et al. 2006; Sasso et al. 2004; Sorkin et al. 2005; Temelkova-Kurktschiev et al. 2000). Postprandial glycemia do show a stronger correlation to disease and mortality than fasting blood glucose (Cavalot et al. 2011; Cavalot et al. 2006; DECODE 1999; DECODE 2001; Sasso et al. 2004; Temelkova-Kurktschiev et al. 2000). The largest risk for cardiovascular disease is observed in persons with postprandial blood glucose values defined as "diabetes" or "impaired glucose tolerance". However, the association between postprandial blood glucose levels and cardiovascular disease shows no threshold level and starts well below the area of hyperglycemia, i.e. an elevated risk is present in the upper areas of "normal blood glucose" (Coutinho et al. 1999; DECODE 2003; Levitan et al. 2004). 
The positive effect of physical training on blood glucose is well documented (Boule et al. 2001; Snowling and Hopkins 2006; Thomas et al. 2006). However, the timing between food ingestion and exercise affects the acute influence of exercise on postprandial glycemia, with the most pronounced effect observed when physical activity is performed short time after food ingestion (Aadland and Høstmark 2008; Bailey and Locke 2015; Caron et al. 1982; Colberg et al. 2014; Dipietro et al. 2013; Dunstan et al. 2012; Gillen et al. 2012; Hashimoto et al. 2013; Hostmark et al. 2006; Larsen et al. 1997; Larsen et al. 1999; Lunde et al. 2012; Nelson et al. 1982; Nygaard et al. 2009; van Dijk et al. 2013a). Even very light or small amounts of postprandial physical activity have the ability to blunt postprandial increases in glycemia effectively (Aadland and Høstmark 2008; Bailey and Locke 2015; Dipietro et al. 2013; Dunstan et al. 2012; Lunde et al. 2012; Nygaard et al. 2009; van Dijk et al. 2013a). However, little is known about the long-term effect of such activity. Light activity as for example walking is inexpensive, without adverse effects and almost everyone can do it (Morris and Hardman 1997).

The purpose of the present study was to test the hypothesis that regular light postprandial physical activity can improve glycemia of persons with hyperglycemia or with high risk of hyperglycemia. 


\section{Materials and methods}

\section{Participants and recruitment process}

We recruited the participants from Lillehammer, Oslo and the surrounding area in Norway, using information in media, posters, local diabetes associations, mosques, temples and community events. Recruitment started in May 2010 and data collection was completed in June 2014. We included hyperglycemic persons (independent of origin) treated with lifestyle change only and south Asian immigrants with high risk of type 2 diabetes according to Ramachandran's risk score for Asian Indians. Hyperglycemia was defined as previously measured fasting venous plasma glucose $\geq 6.1 \mathrm{mmol}^{-1}$ and/or 2 hour glucose tolerance $\geq 7.8$ mmol $\mathrm{L}^{-1}$, and a cut off $>21$ was used for the risk-score according to Ramachandran`s recommendations (Ramachandran et al. 2005). Originally, only hyperglycemic persons were included, but due to a low number of participants (in 2010 and 2011) we changed eligibility to also include Asian immigrants with high risk of diabetes type 2 (from 2012). We considered medication or illnesses directly affecting glycemia (other than hyperglycemia per se) as exclusion criteria.

We chose HbA1c, fasting glucose and 2 hour glucose as primary outcome measures. In power calculations we considered a 5\% improvement in the primary outcomes; HbA1c or glucose as clinical relevant. We expected a standard deviation of 5\% on the change. Accordingly, 20 participants in each group would be enough to detect a clinical relevant improvement with a two-sided test, $\alpha=0.05$ and power $=80 \%$. Interested persons were given detailed written information. A total of 56 persons were randomized to a control group $(\mathrm{CON})$ or an intervention group (INT), of which 16 dropped out after inclusion (Fig. 1). Randomization was done in accordance with the random allocation rule (Lachin 1988). To ensure equal group sizes of $n=20$, the lot from a participant that dropped-out were replaced in the lottery. To limit 
interchange of information from INT to $\mathrm{CON}$, family members or close friends that enrolled at the same time were randomized to the same group. Four persons dropped out between randomization and pre-test (Fig. 1), 12 persons dropped out during the intervention period, whereas 40 persons completed the post-tests with 20 persons in each group. Baseline characteristics of the participants who completed the study are given in table 1 .

\section{Ethics Statement}

The Regional Ethics Committee (REK Sør-Øst, Norway) approved the study, and all subjects gave their written informed consent. The trial and all related studies are registered at clinicaltrials.gov. ID: NCT02536066, URL: https://clinicaltrials.gov/ct2/show/NCT02536066?term=h\%C3\%A5vard+nygaard\&rank=2. The authors confirm that all ongoing and related trials for this intervention are registered. The trial was not registered prior to enrollment because we were not aware of this requirement.

\section{Intervention}

Participants in INT underwent a individual motivation session. Everyone were instructed to add $>30$ minutes of physical activity each day, starting $<30$ minutes after a meal, during the 12 week intervention. However, they were free to do more than 30 minutes, and everyone developed individual targets for the level and pattern of postprandial physical activity during intervention. Individual targets were based on each participant's motivation, wishes and possibilities for performing activity after meals. Our intention was to increase the level of postprandial physical activity as much as possible for each individual in INT. The intervention was "home-based", and they were free to do whatever type of activity they wanted, as long as it involved the legs. Prior to target-setting they were given information about the acute effects of postprandial physical activity on blood glucose (Aadland and 
Høstmark 2008; Caron et al. 1982; Colberg et al. 2014; Colberg et al. 2009; Derave et al. 2007; Dipietro et al. 2013; Dunstan et al. 2012; Hashimoto et al. 2013; Hostmark et al. 2006; Larsen et al. 1997; Larsen et al. 1999; Lunde et al. 2012; Nelson et al. 1982; Nygaard et al. 2009; Peddie et al. 2013; van Dijk et al. 2013a). They were free to choose which of the daily meals that should be followed by physical activity, but they were informed that the effect was anticipated to be largest after meals with largest carbohydrate intake. Furthermore, the participants in INT were told to maintain their usual diet and live as usual. The participants in CON were instructed to maintain their usual lifestyle habits. We contacted the participants in INT by telephone every $2-3$ week during the study period to help them maintain motivation for the intervention.

\section{Measurements}

The participants were instructed not to do intense or exhausting exercise during the last three days leading up to pre or post-test. Light activity (the intervention included) was allowed. Time from the most recent activity bout to post-test was $2 \pm 3$ days for CON and $1 \pm 0$ days for INT (median \pm interquartile range, IQR).

Venous blood samples were analyzed commercially by Furst Medical Laboratories, Oslo. HbA1c was analysed by HPLC- G8, Tosoh Bioscience. Glucose, triglycerides and all cholesterol levels by Advia 2400 Chemistry system, Siemens Healthcare Diagnostics Inc, and insulin and c-peptide by immunoassays, Advia Centaur XP, Siemens Healthcare Diagnostics Inc.

The original protocol included measures of $\mathrm{HbA1c}$ and fasted values of glucose, insulin, triglycerides, HDL cholesterol and LDL cholesterol, as well as 2 hour glucose ( $75 \mathrm{~g}$ glucose challenge), systolic BP, diastolic BP, body weight, waist circumference, dietary recordings, accelerometer recordings and questionnaires. After the $8^{\text {th }}$ participant we also added fasting 
and 2 hour c-peptide, 2 hour insulin and finger sticks with capillary glucose measurements every 15 minute during the 2 hour oral glucose tolerance test. All data were collected by the first author.

In three subjects the 2 hour insulin value exceeded the upper measurement range of the analysis instrument (all three at the pre-test and two of them at post-test), which were 2080 $\mathrm{pmol} \cdot \mathrm{L}^{-1}$. Those values were set to $2080 \mathrm{pmol} \cdot \mathrm{L}^{-1}$ in the analysis. Blood pressure is presented as mean of two measures; one in the fasting state after 5 minutes rest and the other 1 hour after start of glucose intake.

To measure the level of physical activity we used questionnaires, activity diaries and accelerometer recordings. In the questionnaire at the pre-test, the participants were asked about the level of physical activity, defined as walking, bicycling or more intense activity during the 3 months prior to the study. In the questionnaire at the post-test, they were asked about the magnitude of change in such activity from before the study to within the study period. During the entire study period they kept an activity diary which included type of activity, duration, perceived exertion (Borg 1982), and time from end of last meal to start of activity. In the diary, physical activity was defined as all activity involving the legs and lasting $>10$ minutes. Accelerometers were used to estimate the level of physical activity pre study and during study. Before the study, the participants used the accelerometers (ActiGraph GT3X, ActiGraph. LLC, Pensacola, FL, US) for four consecutive days at home; 3 weekdays and 1 day during the weekend. The accelerometers were carried at the right hip, while awake (Trost et al. 2005). This procedure was repeated on the same weekdays in the middle of the study period. The accelerometers registered vertical acceleration 30 times per second in units called counts. Mean count values were stored in 10-second intervals. We downloaded the data to the ActiLife software provided by the manufacturer (ActiGraph, LLC). To control for the influence of wear-time on the total amount of counts we used wear-time computed by the 
software. This was defined as total registration time minus all time with at least 60 consecutive minutes with zero counts, with allowance for up to 1 minute with counts greater than zero. Such accelerometer recordings is regarded as a preferred method for assessing free living physical activity level and the correlation to other methods (e.g. indirect calorimetry) is in the range $r=0.45-0.90$ (Hansen et al. 2014; Trost et al. 2005).

To assess dietary habits, the participants also performed dietary recordings. They did this registration simultaneously as the accelerometer recordings. Every component of every meal was carefully registered by a digital kitchen scale and noted in the diary during this four-day period. Dietary assessment data were analyzed using a nutrient analysis program (Mat på Data 5.0, The Norwegian Food Safety Authority, Oslo, Norway).

\section{Statistics}

We did the statistical analyses with IBM SPSS statistics, version 22.0. Analysis of within group changes and comparisons between groups of within group changes were done with a linear mixed model. Participant number was used as the "repeated subject variable" with random intercept. Group and time (pre, post) were used as fixed factors. The effect of intervention was defined as the group*time interaction. Residuals were checked for normality and homogeneity. Between group comparisons of data sampled only on one time point was done with independent t-tests. Correlations were done with Pearson`s r. However, there were some exceptions since the residuals for the comparison of the pre and post values for 2 hour insulin (CON and INT) and LDL cholesterol (INT) were indistinctly skewed. We performed both parametric and nonparametric tests (Wilcoxon) for the within group comparisons, and chose to report the highest $\mathrm{p}$ value for each variable. However, choose of method did not affect whether any difference was significant or not. The level of physical activity prior to 
study and during study were markedly skewed (both CON and INT) and p values were obtained with Mann Whitney U. The $\alpha$-level was set at 0.05 and a $p$ value $<0.1$ was considered as a tendency towards statistical significance. The data are presented as means \pm SD except from physical activity prior to and during study, which are presented as median \pm IQR. The result section is based upon the 40 participants that completed the study, unless intention-totreat or otherwise are stated. All 40 are included, regardless of whether they did all the recommended activity or not, unless otherwise stated. Missing values in the intention-to-treat analysis (post-test results of dropouts) were replaced by the baseline values.

\section{Results}

\section{Dietary recordings}

12 participants in CON and 17 in INT completed the dietary registration. All 11 participants who did not complete the dietary registration reported that they were not on a diet low on carbohydrates. Data from the recordings are given in table 2. Between groups analysis showed that the fat consumption decreased in INT compared to CON from pre to midway ( $p=0.010)$, and dietary fiber decreased in CON compared to INT $(\mathrm{p}=0.015)$.

\section{Level of physical activity}

Activity levels reported in questionnaires are shown in table 3. Prior to the study the participants in CON reported 12 minutes more physical activity per day for the last three months than INT (defined as walking, bicycling or more intense activity, $p=0.001$ ). The 
participants in INT reported an increase in activity level from before the intervention to within the intervention period of $41 \pm 25$ minutes per day, while CON reported an increase of $2 \pm 16$ ( $<<0.001$ between groups). Results from accelerometer measurements are presented in table 4 . INT had $44 \pm 70 \%$ increase in accelerometer counts from before intervention to within intervention. The corresponding value in $\mathrm{CON}$ was $5 \pm 56 \%$. However, the difference between INT and CON was only borderline significant $(\mathrm{p}=0.061)$. One subject reported swimming as main activity during INT (without the accelerometer). Results from activity diaries showed that INT performed $1.3 \pm 0.8$ bouts of physical activity per day during intervention (table 3 ). Each bout lasted $56 \pm 21$ minutes, with an intensity of $11.3 \pm 1.0$ on Borg RPE scale (physical activity was defined as all activity involving the legs and lasting $>10$ minutes). The total amount of activity performed per day tended to be higher than in CON $(1.0 \pm 0.7$ bouts per day with duration $53 \pm 36$ minutes per bout, $\mathrm{p}=0.085)$. The activity of INT started $30 \pm 13$ minutes after the last meal, which was earlier than the corresponding value in CON $(100 \pm 57$ minutes after meal, $p=0.001)$. The pattern of physical activity in INT is shown in figure 2 in relation to the blood glucose curve during the glucose tolerance test. The predominant activity during intervention in INT was walking, but there was also registered some bicycling, gardening and swimming.

\section{Health related outcomes}

One of the participants reported some flatulence as a result of the intervention, otherwise no side effects was reported. Results from blood samples, anthropometry and blood pressure are shown in table 5. Neither intention-to-treat analysis, nor analysis with only the participants that completed the study revealed any effect of intervention on HbAlc, glucose, insulin or cpeptide measures. There was no significant interaction between the effect of intervention and 
carbohydrate intake or ethnicity. Blood glucose curves during the 2 hour oral glucose

tolerance test are shown in figure 2. There was no significant correlation between the baseline values and the pre to post change in the glycemic variables.

The change in level of physical activity reported by questionnaire or measured by accelerometer did not correlate significantly with change in any glycemic variable in INT.

Correlation coefficients to $\mathrm{HbA1c}$, fasting and 2 hour glucose were $0.302,-0.071$ and 0.262

for change in physical activity based on questionnaire results and $0.236,0.005$ and -0.003 for the change in physical activity based on accelerometer counts. A subgroup analysis in INT after exclusions of the participants that did report a change in physical activity level of $<30$ minutes per day, showed that the participants who added more than 30 minutes of activity each day $(n=14)$ did not have any effect of the intervention on HbA1c or glucose values. Accelerometer data confirmed the increase in activity level in this group, with a mean increase from pre to midway by $55 \pm 77 \%(\mathrm{p}<0.001)$. An additional exclusion (per protocol analysis) of the participants that started activity $>30$ minutes after the last meal did not change this result $(n=9)$. Accelerometer data confirmed the increase in activity level also in this group, with a mean increase from pre to midway by $61 \pm 70 \%(\mathrm{p}<0.001)$.

Among the lipoproteins (table 5) there was a difference between groups in the change of LDL cholesterol from pre to post $(\mathrm{p}=0.036)$. Waist circumference and body weight were reduced in INT compared to $\mathrm{CON}$ ( $\mathrm{p}=0.031$ and $\mathrm{p}=0.009$ respectively). 


\section{Discussion}

The main finding in this study is that the addition of daily postprandial physical activity for 12 weeks did not improve glycemia in the participants who was either hyperglycemic or defined as persons with high risk for type 2 diabetes.

The results from the questionnaires and accelerometers confirm that the participants in the intervention group actually increased their level of physical activity. The accelerometer results may though have underestimated the increases in activity level, since some of the participant in the intervention group practiced swimming (without the accelerometer) and bicycling as regular activities during intervention. Bicycling is poorly registered by accelerometer worn on the hip (Hansen et al. 2014). Results from the activity diary that were recorded during the study also suggest that the intervention group increased their level of physical activity, since the reported activity level tended to be higher than in the control group. However, the results from the activity diaries are difficult to interpret, since there is no baseline data, and as suggested by the results from the questionnaires, there may have been a higher baseline activity level in the control group than in the intervention group. The increased activity level in the intervention group induced a reduction in body weight and waist circumference. The body weight and waist circumference reductions were however just modest. It might therefore be speculated that the reported changes in activity level is overestimated, or that a dietary compensation to the increased activity level have occurred. Such a dietary compensation is however not supported by the results from the dietary recordings. The intensity and duration of the added activity may therefore have been too low to cause major reduction in fat mass.

Independent of the level of activity performed it seems convincing that the intervention group had changed their activity pattern with regard to timing to the preceding meal. A start of 
activity 30 minutes after the last meal was much earlier than the control group and the variability in this time was low between the participants in the intervention group. This timing between food intake and onset of physical activity has been suggested to be ideal for lowering postprandial glycemia in diabetic persons, due to a high insulin-to-glucagon ratio at this point (Chacko 2014). A high insulin-to-glucagon ratio would in turn inhibit the counter regulatory increase of hepatic glucose output that will occur when exercise is done at other times. In accordance with this, it has been shown that the glucose lowering effect of physical activity depends on the glucose level at onset of activity. If the glucose level is high, the subsequent decrease during physical activity will be larger (Gaudet-Savard et al. 2007). It is very likely that glycemia is at its highest 30 minutes into the postprandial phase in persons with moderate glycemia (Derave et al. 2007; Dipietro et al. 2013; Dunstan et al. 2012; Little et al. 2014; Lunde et al. 2012; Nelson et al. 1982). Thus, the lack of improvement in glycemia was present despite changes in activity patterns that should be ideal for blunting of glycemic excursions. The reported duration of the light activity bouts in the intervention group is also long enough to blunt postprandial glycemia substantially (Dipietro et al. 2013; Dunstan et al. 2012; Lunde et al. 2012; Nygaard et al. 2009). An alternative could have been to do shorter activity bouts after a higher number of meals (Dipietro et al. 2013). It is however, not known if such an approach would have been more successful, and it might have been harder to carry out for the participants.

Some of the participants in the intervention group did not add $>30$ minutes of physical activity each day, and did not start $<30$ minutes after a meal which they were told to do. However, the exclusion of these participants in the analysis did not affect the results. Furthermore, there was no significant correlation between the amount of postprandial physical activity added during intervention and the effect on glycemia. Indeed, if any relationship was 
present, it was in disfavor of the hypothesis. This observations reinforce our findings of lack of chronic effect of the intervention on glycemic response.

One might question whether the results is influenced by the fact that the sample was rather heterogeneous. There was however no significant correlation between the severity of hyperglycemia and the effect of intervention. Heterogeneity between groups might also have influenced the results. The most pronounced difference between groups were observed in baseline physical activity, with a higher level in the control group compared to the intervention group. It is however hard to interpret this as a possible explanation of lack of effect in the intervention group, since a low level of physical activity intuitively should enlarge the potential for an effect of an activity intervention. A corresponding reasoning can be done for glucose tolerance that appear to have been most impaired in the intervention group. In addition, there is a lack of positive effect also within the intervention group. This reinforce the impression that the lack of differences between groups is not a result of baseline characteristics in the intervention group.

Among the participants who were of different ethnicities, there was a variation in carbohydrate intake. A traditional Asian diet represent a higher glycemic load than a traditional European diet (Burden et al. 1994; Hu et al. 2012), and some of the ethnic European participants did in fact report to be on a low carbohydrate diet. Low carbohydrate intake entails smaller postprandial excursions in blood glucose compared to a large intake and may therefore decrease the potential for a glycemic effect of physical activity. There was no statistical relationship between the amount of carbohydrate intake and the effect of the intervention, but it cannot be ruled out that a low carbohydrate intake in some of the participants has decreased the possibility of finding an effect of the intervention. 
The positive effect of regular exercise on hyperglycemia is well documented (Boule et al. 2001; Snowling and Hopkins 2006; Thomas et al. 2006). As shown in a meta-analysis by Qui et al. (2014), also light activity like walking has the ability to decrease HbAlc more than what was observed in the present study. However, this meta-analysis included studies on diabetic participants only, and as mentioned earlier, the glucose lowering effect of physical activity may certainly depend on the baseline glycemic status (Aadland and Høstmark 2008; Church et al. 2010; Hordern et al. 2008; Mikines et al. 1988; Nygaard et al. 2009; Snowling and Hopkins 2006; Van Dijk et al. 2013b; Walker et al. 1999). Nevertheless, the amount of lightintensity physical activity measured by accelerometers is associated with glucose tolerance in a population without known diabetes (Healy et al. 2007). Furthermore, Walker et al. (1999) found that a walking program, comparable to the intervention in the present study, entailed a significant reduction in glycemia also in normoglycemic individuals. Based on previous results of low intensity physical activity interventions and the fact that light postprandial physical activity entails considerable acute reductions of postprandial glycemia (Aadland and Høstmark 2008; Bailey and Locke 2015; Dipietro et al. 2013; Dunstan et al. 2012; Lunde et al. 2012; Nygaard et al. 2009; van Dijk et al. 2013a), it was reasonable to expect a reduction in glycemia also in the present study. The lack of effect raises the question whether some of the anticipated adaptations to regular physical activity are blunted as a result of the nutritional status during postprandial activity.

One possible physiological explanation of the lack of positive results of the intervention is related to intramyocellular lipids. Accumulation of intramyocellular lipids is believed to be an important mechanism behind insulin resistance (Pan et al. 1997; Zhang et al. 2010). These lipids are used as an energy source during exercise. Glucose feeding during exercise has the ability to decrease the release of hormone sensitive lipase which is the rate-limiting enzyme in the breakdown of intramyocellular lipids (Watt et al. 2004). A few studies have demonstrated 
a larger breakdown of intramyocellular lipids after postabsorptive exercise compared to exercise in the carbohydrate fed state or after exercise with carbohydrate feeding, in healthy participants (De Bock et al. 2005; Van Proeyen et al. 2011). Furthermore, exercise in healthy participants in the fasted state have advantageous effects on insulin sensitivity during a fatrich high-energy diet compared to exercise accompanied with glucose intake (Van Proeyen et al. 2010).

All types of physical activity, light activity included, is associated with major health benefits both in diabetic populations (Gregg et al. 2003; Hu et al. 2004) and in the general population (Ekblom-Bak et al. 2013; Manson et al. 1999). Despite growing knowledge about exercise as an effective strategy to improve glycemic control, many diabetes patients do not engage in structured exercise programs (Praet and van Loon 2008). Light physical activity like walking, is simple, inexpensive, without adverse effects and may therefore be a good strategy for implementing physical activity (Morris and Hardman 1997). The results of the present study should therefore not be interpreted as if light physical activity does not matter to health. Indeed, health benefits like reduction of body weight, waist circumference and LDL cholesterol were observed in the present study. However, our results do not support the notion that physical activity should be performed just after a meal if the purpose is to improve glycemia. The study should be interpreted with care, with regard to the methodological concerns and potential bias mentioned above. The results contrasts results from a review based on findings in acute studies, which concludes that physical activity should be done in the postprandial state for improving postprandial glycemia, at least if carbohydrates is a main nutrient (Haxhi et al. 2013). Our results may be generalized to people in the upper normoglycemic areas or people with moderate hyperglycemia. Postprandial physical activity may affect glycemia differently in people with severe hyperglycemia. Also type 1 diabetes, which is not caused by insulin resistance, may be a suitable area for future research on 
postprandial physical activity. There is a need for a direct comparison of postabsorptive and postprandial physical activity in the long term. Furthermore, the effects on other health parameters in addition to glycemia should be explored. For example, there are indications that postprandial glycemic excursions leads to cardiovascular diseases via several mechanisms that can be assessed (Standl et al. 2011).

\section{Conclusion}

The present study does not seem to support the notion that regular light postprandial physical activity improves blood glucose concentrations in the long term in persons with hyperglycemia or with high risk of hyperglycemia.

\section{Acknowledgments}

Thanks to Torstein Midtlien for contribution to the pilot study.

\section{Conflict of interest}

The authors report no conflicts of interest associated with the manuscript.

\section{References}

Aadland, E. and Høstmark, A.T. 2008. Very light Physical Activity after a Meal Blunts the Rise in Blood Glucose and Insulin. Open Nutr. J. 2: 94-99. 
Bailey, D.P. and Locke, C.D. 2015. Breaking up prolonged sitting with light-intensity walking improves postprandial glycemia, but breaking up sitting with standing does not. J. Sci. Med. Sport, 18(3): 294-298. doi:10.1016/j.jsams.2014.03.008

Borg, G.A. 1982. Psychophysical bases of perceived exertion. Med. Sci. Sports Exerc. 14(5): 377-381. PMID:7154893

Boule, N.G., Haddad, E., Kenny, G.P., Wells, G.A., and Sigal, R.J. 2001. Effects of exercise on glycemic control and body mass in type 2 diabetes mellitus: a meta-analysis of controlled clinical trials. JAMA, 286(10): 1218-1227. PMID:11559268

Burden, M.L., Samanta, A., Spalding, D., and A.C., B. 1994. A comparison of the glycaemic and insulinaemic effects of an Asian and a European meal. Practical Diabetes, 11(5): 208-211.

Caron, D., Poussier, P., Marliss, E.B., and Zinman, B. 1982. The effect of postprandial exercise on meal-related glucose intolerance in insulin-dependent diabetic individuals. Diabetes Care, 5(4): 364-369. PMID:6759076

Cavalot, F., Pagliarino, A., Valle, M., Di Martino, L., Bonomo, K., Massucco, P. et al. 2011. Postprandial blood glucose predicts cardiovascular events and all-cause mortality in type 2 diabetes in a 14-year follow-up: lessons from the San Luigi Gonzaga Diabetes Study. Diabetes Care, 34(10): 2237-2243. doi:10.2337/dc10-2414

Cavalot, F., Petrelli, A., Traversa, M., Bonomo, K., Fiora, E., Conti, M. et al. 2006.

Postprandial blood glucose is a stronger predictor of cardiovascular events than fasting blood glucose in type 2 diabetes mellitus, particularly in women: lessons from the San Luigi Gonzaga Diabetes Study. J. Clin. Endocrinol. Metab. 91(3): 813-819. doi:10.1210/jc.2005-1005

Chacko, E. 2014. Why exercise before breakfast may not be for diabetes patients. Conn. Med. 78(9): 517-520. PMID:25675589 
Chiasson, J.L., Josse, R.G., Gomis, R., Hanefeld, M., Karasik, A., and Laakso, M. 2003. Acarbose treatment and the risk of cardiovascular disease and hypertension in patients with impaired glucose tolerance: the STOP-NIDDM trial. JAMA, 290(4): 486-494. PMID:12876091

Church, T.S., Blair, S.N., Cocreham, S., Johannsen, N., Johnson, W., Kramer, K. et al. 2010. Effects of aerobic and resistance training on hemoglobin A1c levels in patients with type 2 diabetes: a randomized controlled trial. JAMA, 304(20): 2253-2262.

PMID:21098771

Colberg, S.R., Grieco, C.R., and Somma, C.T. 2014. Exercise effects on postprandial glycemia, mood, and sympathovagal balance in type 2 diabetes. J. Am. Med. Dir. Assoc. 15(4): 261-266. doi:10.1016/j.jamda.2013.11.026

Colberg, S.R., Zarrabi, L., Bennington, L., Nakave, A., Thomas Somma, C., Swain, D.P. et al. 2009. Postprandial walking is better for lowering the glycemic effect of dinner than pre-dinner exercise in type 2 diabetic individuals. J. Am. Med. Dir. Assoc. 10(6): 394397. PMID:19560716

Coutinho, M., Gerstein, H.C., Wang, Y., and Yusuf, S. 1999. The relationship between glucose and incident cardiovascular events. A metaregression analysis of published data from 20 studies of 95,783 individuals followed for 12.4 years. Diabetes Care, 22(2): 233-240. PMID:10333939

De Bock, K., Richter, E.A., Russell, A.P., Eijnde, B.O., Derave, W., Ramaekers, M. et al. 2005. Exercise in the fasted state facilitates fibre type-specific intramyocellular lipid breakdown and stimulates glycogen resynthesis in humans. J. Physiol. 564(Pt 2): 649660. PMID:15705646

DECODE. 1999. Glucose tolerance and mortality: comparison of WHO and American Diabetes Association diagnostic criteria. The DECODE study group. European 
Diabetes Epidemiology Group. Diabetes Epidemiology: Collaborative analysis Of Diagnostic criteria in Europe. Lancet, 354(9179): 617-621. PMID:10466661

DECODE. 2001. Glucose tolerance and cardiovascular mortality: comparison of fasting and 2-hour diagnostic criteria. Arch. Intern. Med. 161(3): 397-405. PMID:11176766

DECODE. 2003. Is the current definition for diabetes relevant to mortality risk from all causes and cardiovascular and noncardiovascular diseases? Diabetes Care, 26(3): 688696. PMID:12610023

Derave, W., Mertens, A., Muls, E., Pardaens, K., and Hespel, P. 2007. Effects of postabsorptive and postprandial exercise on glucoregulation in metabolic syndrome. Obesity, 15(3): 704-711. PMID:17372321

Dipietro, L., Gribok, A., Stevens, M.S., Hamm, L.F., and Rumpler, W. 2013. Three 15-min Bouts of Moderate Postmeal Walking Significantly Improves 24-h Glycemic Control in Older People at Risk for Impaired Glucose Tolerance. Diabetes Care, 36(10): 32623268. PMID:23761134

Dunstan, D.W., Kingwell, B.A., Larsen, R., Healy, G.N., Cerin, E., Hamilton, M.T. et al. 2012. Breaking up prolonged sitting reduces postprandial glucose and insulin responses. Diabetes Care, 35(5): 976-983. PMID: 22374636

Ekblom-Bak, E., Ekblom, B., Vikstrom, M., de Faire, U., and Hellenius, M.L. 2013. The importance of non-exercise physical activity for cardiovascular health and longevity. Br. J. Sports Med. 48(3): 233-238. doi: 10.1136/bjsports-2012-092038

Gaudet-Savard, T., Ferland, A., Broderick, T.L., Garneau, C., Tremblay, A., Nadeau, A. et al. 2007. Safety and magnitude of changes in blood glucose levels following exercise performed in the fasted and the postprandial state in men with type 2 diabetes. Eur. J. Cardiovasc. Prev. Rehabil. 14(6): 831-836. doi:10.1097/HJR.0b013e3282efaf38 
Gillen, J.B., Little, J.P., Punthakee, Z., Tarnopolsky, M.A., Riddell, M.C., and Gibala, M.J. 2012. Acute high-intensity interval exercise reduces the postprandial glucose response and prevalence of hyperglycaemia in patients with type 2 diabetes. Diabetes Obes. Metab. 14(6): 575-577. doi:10.1111/j.1463-1326.2012.01564.x

Gregg, E.W., Gerzoff, R.B., Caspersen, C.J., Williamson, D.F., and Narayan, K.M. 2003. Relationship of walking to mortality among US adults with diabetes. Arch. Intern. Med. 163(12): 1440-1447. PMID:12824093

Hanefeld, M., Chiasson, J.L., Koehler, C., Henkel, E., Schaper, F., and TemelkovaKurktschiev, T. 2004. Acarbose slows progression of intima-media thickness of the carotid arteries in subjects with impaired glucose tolerance. Stroke, 35(5): 1073-1078. doi:10.1161/01.STR.0000125864.01546.f2

Hansen, B.H., Bortnes, I., Hildebrand, M., Holme, I., Kolle, E., and Anderssen, S.A. 2014. Validity of the ActiGraph GT1M during walking and cycling. J. Sports Sci. 32(6): 510-516. doi:10.1080/02640414.2013.844347

Hashimoto, S., Hayashi, S., Yoshida, A., and Naito, M. 2013. Acute effects of postprandial aerobic exercise on glucose and lipoprotein metabolism in healthy young women. J. Atheroscler. Thromb. 20(2): 204-213. PMID:23154577

Haxhi, J., Scotto di Palumbo, A., and Sacchetti, M. 2013. Exercising for metabolic control: is timing important? Ann. Nutr. Metab. 62(1): 14-25. doi:10.1159/000343788

Healy, G.N., Dunstan, D.W., Salmon, J., Cerin, E., Shaw, J.E., Zimmet, P.Z. et al. 2007. Objectively measured light-intensity physical activity is independently associated with 2-h plasma glucose. Diabetes Care, 30(6): 1384-1389. doi:10.2337/dc07-0114

Hordern, M.D., Cooney, L.M., Beller, E.M., Prins, J.B., Marwick, T.H., and Coombes, J.S. 2008. Determinants of changes in blood glucose response to short-term exercise training in patients with Type 2 diabetes. Clin. Sci. 115(9): 273-281. PMID:18254721 
Hostmark, A.T., Ekeland, G.S., Beckstrom, A.C., and Meen, H.D. 2006. Postprandial light physical activity blunts the blood glucose increase. Prev. Med. 42(5): 369-371. PMID:16549107

Hu, E.A., Pan, A., Malik, V., and Sun, Q. 2012. White rice consumption and risk of type 2 diabetes: meta-analysis and systematic review. BMJ. 344: e1454. doi:10.1136/bmj.e1454

Hu, G., Eriksson, J., Barengo, N.C., Lakka, T.A., Valle, T.T., Nissinen, A. et al. 2004. Occupational, commuting, and leisure-time physical activity in relation to total and cardiovascular mortality among Finnish subjects with type 2 diabetes. Circulation, 110(6): 666-673. doi:10.1161/01.CIR.0000138102.23783.94

IDF. 2015. Diabetes Atlas: International Diabetes Federation.

Lachin, J.M. 1988. Properties of simple randomization in clinical trials. Control. Clin. Trials. 9(4): 312-326. PMID:3203523

Larsen, J.J., Dela, F., Kjaer, M., and Galbo, H. 1997. The effect of moderate exercise on postprandial glucose homeostasis in NIDDM patients. Diabetologia, 40(4): 447-453. PMID:9112022

Larsen, J.J., Dela, F., Madsbad, S., and Galbo, H. 1999. The effect of intense exercise on postprandial glucose homeostasis in type II diabetic patients. Diabetologia, 42(11): 1282-1292. PMID:10550411

Levitan, E.B., Song, Y., Ford, E.S., and Liu, S. 2004. Is nondiabetic hyperglycemia a risk factor for cardiovascular disease? A meta-analysis of prospective studies. Arch. Intern. Med. 164(19): 2147-2155. PMID:15505129

Little, J.P., Jung, M.E., Wright, A.E., Wright, W., and Manders, R.J. 2014. Effects of highintensity interval exercise versus continuous moderate-intensity exercise on 
postprandial glycemic control assessed by continuous glucose monitoring in obese adults. Appl. Physiol. Nutr. Metab. 39(7): 835-841. doi:10.1139/apnm-2013-0512

Lunde, M.S., Hjellset, V.T., and Hostmark, A.T. 2012. Slow post meal walking reduces the blood glucose response: an exploratory study in female pakistani immigrants. J. Immigr. Minor. Health. 14(5): 816-822. doi:10.1007/s10903-012-9574-x

Manson, J.E., Hu, F.B., Rich-Edwards, J.W., Colditz, G.A., Stampfer, M.J., Willett, W.C. et al. 1999. A prospective study of walking as compared with vigorous exercise in the prevention of coronary heart disease in women. N. Engl. J. Med. 341(9): 650-658. PMID:10460816

Mikines, K.J., Farrell, P.A., Sonne, B., Tronier, B., and Galbo, H. 1988. Postexercise doseresponse relationship between plasma glucose and insulin secretion. J. Appl. Physiol. 64(3): 988-999. PMID:3284873

Morris, J.N. and Hardman, A.E. 1997. Walking to health. Sports Med. 23(5): 306-332. PMID:9181668

Nakagami, T., Qiao, Q., Tuomilehto, J., Balkau, B., Tajima, N., Hu, G. et al. 2006. Screendetected diabetes, hypertension and hypercholesterolemia as predictors of cardiovascular mortality in five populations of Asian origin: the DECODA study. Eur. J. Cardiovasc. Prev. Rehabil. 13(4): 555-561. PMID:16874145

Nelson, J.D., Poussier, P., Marliss, E.B., Albisser, A.M., and Zinman, B. 1982. Metabolic response of normal man and insulin-infused diabetics to postprandial exercise. The Am. J. Physiol. 242(5): E309-316. PMID:7044140

Nygaard, H., Tomten, S.E., and Hostmark, A.T. 2009. Slow postmeal walking reduces postprandial glycemia in middle-aged women. Appl. Physiol. Nutr. Metab. 34(6): 1087-1092. PMID:20029518 
Pan, D.A., Lillioja, S., Kriketos, A.D., Milner, M.R., Baur, L.A., Bogardus, C. et al. 1997. Skeletal muscle triglyceride levels are inversely related to insulin action. Diabetes, 46(6): 983-988. PMID:9166669

Peddie, M.C., Bone, J.L., Rehrer, N.J., Skeaff, C.M., Gray, A.R., and Perry, T.L. 2013. Breaking prolonged sitting reduces postprandial glycemia in healthy, normal-weight adults: a randomized crossover trial. Am. J. Clin. Nutr. 98(2): 358-366. doi:10.3945/ajen.112.051763

Praet, S.F. and van Loon, L.J. 2008. Exercise: the brittle cornerstone of type 2 diabetes treatment. Diabetologia, 51(3): 398-401. doi:10.1007/s00125-007-0910-y

Qiu, S., Cai, X., Schumann, U., Velders, M., Sun, Z., and Steinacker, J.M. 2014. Impact of walking on glycemic control and other cardiovascular risk factors in type 2 diabetes: a meta-analysis. PloS one, 9(10): e109767. doi:10.1371/journal.pone.0109767

Ramachandran, A., Snehalatha, C., Vijay, V., Wareham, N.J., and Colagiuri, S. 2005. Derivation and validation of diabetes risk score for urban Asian Indians. Diabetes Res. Clin. Pract. 70(1): 63-70. PMID: 16126124

Sasso, F.C., Carbonara, O., Nasti, R., Campana, B., Marfella, R., Torella, M. et al. 2004. Glucose metabolism and coronary heart disease in patients with normal glucose tolerance. JAMA, 291(15): 1857-1863. doi:10.1001/jama.291.15.1857

Snowling, N.J. and Hopkins, W.G. 2006. Effects of different modes of exercise training on glucose control and risk factors for complications in type 2 diabetic patients: a metaanalysis. Diabetes Care, 29(11): 2518-2527. PMID:17065697

Sorkin, J.D., Muller, D.C., Fleg, J.L., and Andres, R. 2005. The relation of fasting and 2-h postchallenge plasma glucose concentrations to mortality: data from the Baltimore Longitudinal Study of Aging with a critical review of the literature. Diabetes Care, 28(11): 2626-2632. PMID:16249530 
Standl, E., Schnell, O., and Ceriello, A. 2011. Postprandial hyperglycemia and glycemic variability: should we care? Diabetes Care, 34 Suppl 2: S120-127. doi:10.2337/dc11s206

Temelkova-Kurktschiev, T.S., Koehler, C., Henkel, E., Leonhardt, W., Fuecker, K., and Hanefeld, M. 2000. Postchallenge plasma glucose and glycemic spikes are more strongly associated with atherosclerosis than fasting glucose or HbAlc level. Diabetes Care, 23(12): 1830-1834. PMID:11128361

Thomas, D.E., Elliott, E.J., and Naughton, G.A. 2006. Exercise for type 2 diabetes mellitus. Cochrane Database Syst Rev. 3: CD002968. doi:10.1002/14651858.CD002968.pub2 Trost, S.G., McIver, K.L., and Pate, R.R. 2005. Conducting accelerometer-based activity assessments in field-based research. Med. Sci. Sports Exerc. 37(11 Suppl): S531-543. PMID: 16294116

van Dijk, J.W., Venema, M., van Mechelen, W., Stehouwer, C.D., Hartgens, F., and van Loon, L.J. 2013a. Effect of moderate-intensity exercise versus activities of daily living on 24-hour blood glucose homeostasis in male patients with type 2 diabetes. Diabetes Care, 36(11): 3448-3453. doi:10.2337/dc12-2620

Van Dijk, J.W., Manders, R.J., Canfora, E.E., Mechelen, W.V., Hartgens, F., Stehouwer, C.D. et al. 2013b. Exercise and 24-h glycemic control: equal effects for all type 2 diabetes patients? Med. Sci. Sports Exerc. 45(4): 628-635. doi:10.1249/MSS.0b013e31827ad8b4

Van Proeyen, K., Szlufcik, K., Nielens, H., Ramaekers, M., and Hespel, P. 2011. Beneficial metabolic adaptations due to endurance exercise training in the fasted state. J. Appl.

Physiol. 110(1): 236-245. PMID:21051570 
Van Proeyen, K., Szlufcik, K., Nielens, H., Pelgrim, K., Deldicque, L., Hesselink, M. et al. 2010. Training in the fasted state improves glucose tolerance during fat-rich diet. J. Physiol. 588(Pt 21): 4289-4302. PMID:20837645

Walker, K.Z., Piers, L.S., Putt, R.S., Jones, J.A., and O'Dea, K. 1999. Effects of regular walking on cardiovascular risk factors and body composition in normoglycemic women and women with type 2 diabetes. Diabetes Care, 22(4): 555-561.

PMID:10189531

Watt, M.J., Krustrup, P., Secher, N.H., Saltin, B., Pedersen, B.K., and Febbraio, M.A. 2004. Glucose ingestion blunts hormone-sensitive lipase activity in contracting human skeletal muscle. Am. J. Physiol. Endocrinol. Metab. 286(1): E144-150. doi:10.1152/ajpendo.00198.2003

Zhang, L., Keung, W., Samokhvalov, V., Wang, W., and Lopaschuk, G.D. 2010. Role of fatty acid uptake and fatty acid beta-oxidation in mediating insulin resistance in heart and skeletal muscle. Biochim. Biophys. Acta. 1801(1): 1-22. PMID:19782765 


\section{Tables}

Table 1. Baseline characteristics of the participants that completed the study

\begin{tabular}{|lll|}
\hline & \multicolumn{1}{c}{ CON } & \multicolumn{1}{l}{ INT } \\
Participants, $\mathrm{n}$ & 20 & 20 \\
Previously diagnosed with hyperglycemia, $\mathrm{n}$ & 10 & 13 \\
$\quad$ of which diagnosed with diabetes, $\mathrm{n}$ & 5 & 5 \\
Time since diagnosis of hyperglycemia, months & $26 \pm 27$ & $35 \pm 39$ \\
Included by Ramachandran 's risk score, $\mathrm{n}$ & 10 & 7 \\
Asian origin, $\mathrm{n}$ & 11 & 12 \\
European origin, $\mathrm{n}$ & 9 & 8 \\
Female, $\mathrm{n}$ & 7 & 6 \\
Age, years & $46 \pm 8$ & $53 \pm 9$ \\
Postmenopausal women, $\mathrm{n}$ & 5 & 5 \\
Height, cm & $172 \pm 10$ & $168 \pm 10$ \\
Body weight, $\mathrm{kg}$ & $80.7 \pm 17.8$ & $74.4 \pm 10.7$ \\
BMI, kg m ${ }^{-2}$ & $27.4 \pm 4.5$ & $26.3 \pm 2.4$ \\
\hline
\end{tabular}

Hyperglycemia was defined as previously measured fasting venous plasma glucose $\geq 6.1$

$\mathrm{mmol} \mathrm{L}^{-1}$ and/or 2 hour glucose tolerance $\geq 7.8 \mathrm{mmol} \mathrm{L}^{-1}$. Diabetes was defined as previously measured fasting venous plasma glucose $\geq 7 \mathrm{mmol}^{-1} \mathrm{~L}^{-1}$ and/or 2 hour glucose tolerance $\geq 11.1$

$\mathrm{mmol} \mathrm{L}^{-1}$. A cut off $>21$ was used for the risk-score according to Ramachandran`s recommendations (Ramachandran et al. 2005). 
Table 2. Dietary intake per day.

\begin{tabular}{|c|c|c|c|c|}
\hline & \multicolumn{2}{|l|}{$\mathrm{CON}, \mathrm{n}=12$} & \multicolumn{2}{|l|}{ INT, $n=17$} \\
\hline & Pre & Midway & Pre & Midway \\
\hline Energy intake, KJ & $8279 \pm 2150$ & $8043 \pm 1819$ & $8231 \pm 2216$ & $7364 \pm 1602 \$$ \\
\hline Protein, $\mathrm{g}$ & $86 \pm 18$ & $83 \pm 14$ & $88 \pm 24$ & $83 \pm 26$ \\
\hline Fat, $g$ & $78 \pm 25$ & $84 \pm 28$ & $82 \pm 39$ & $66 \pm 32 * \#$ \\
\hline $\mathrm{CHO}, \mathrm{g}$ & $212 \pm 87$ & $193 \pm 68$ & $199 \pm 97$ & $194 \pm 88$ \\
\hline Mono + disaccharide, $g$ & $91 \pm 62$ & $85 \pm 46$ & $72 \pm 39$ & $61 \pm 29 \$$ \\
\hline Starch, g & $117 \pm 45$ & $105 \pm 36$ & $126 \pm 77$ & $131 \pm 72$ \\
\hline Added sugar, $\mathrm{g}$ & $36 \pm 46$ & $35 \pm 26$ & $26 \pm 24$ & $21 \pm 18$ \\
\hline Dietary fiber, $g$ & $30 \pm 12$ & $22 \pm 9 *$ & $23 \pm 8$ & $23 \pm 8 \quad \#$ \\
\hline \multicolumn{5}{|c|}{ Mean \pm SD calculated from four days dietary recordings performed before and during the study } \\
\hline
\end{tabular}




\section{Table 3. Physical activity patterns.}

\begin{tabular}{|lll|}
\hline \multicolumn{1}{|l}{ Cuestionnaire: } & INT \\
Physical activity level pre study, min per day (median $\pm \mathrm{IQR})$ & $21 \pm 22$ & $2 \pm 17^{* *}$ \\
Change from pre to during study, min per day & $2 \pm 16$ & $41 \pm 25^{* *}$ \\
\hline Physical activity diary: & & $58 \pm 72 \$$ \\
Physical activity during study, min per day (median \pm IQR) & $38 \pm 48$ & $1.3 \pm 0.8$ \\
$\begin{array}{l}\text { Daily bouts of physical activity } \\
\text { Duration per bout of physical activity during intervention, min }\end{array}$ & $53 \pm 36$ & $56 \pm 21$ \\
Time between physical activity and the last meal, min & $100 \pm 57$ & $30 \pm 13 * *$ \\
Perceived exertion (Borg 6-20 scale) & $11 \pm 2$ & $11 \pm 1$ \\
\hline
\end{tabular}

Mean values \pm SD except from physical activity pre and during study, which are median \pm IQR.

Values are calculated from activity diaries of the 12 week study period, except from "Physical activity level pre intervention" and "changes from pre intervention", which was asked for in questionnaires pre and post intervention. All participants answered the questionnaire, while 16 and 20 fulfilled the activity diary in CON and INT respectively. Note that the definition of physical activity differed in the questionnaires vs the diary. $\$=\mathrm{p}<0.1$ between groups, ${ }^{* *}=\mathrm{p}<0.001$ between groups. 
Table 4. Accelerometer data.

\begin{tabular}{|lllll|}
\hline & \multicolumn{2}{c}{ CON, $\mathrm{n}=18$} & \multicolumn{2}{c|}{ INT, $\mathrm{n}=20$} \\
& Pre & Midway & Pre & Midway \\
Wear-time, & $14.4 \pm 2.2$ & $13.4 \pm 2.7$ & $15.3 \pm 1.7$ & $14.2 \pm 2.8 *$ \\
hours per day & & & & \\
Counts per day & $339026 \pm 187319$ & $320632 \pm 203603$ & $292602 \pm 150506$ & $379281 \pm 178849 * \$$ \\
\hline
\end{tabular}

Mean \pm SD calculated from four days accelerometer recordings performed before and during the 12 week study period (midway). $*=\mathrm{p}<0.05$ within group. $\$=\mathrm{p}<0.1$ between groups, change from pre to during study. 18 in CON and 20 in INT completed the accelerometer recordings. 
Table 5. Main results.

\begin{tabular}{|c|c|c|c|c|}
\hline & \multicolumn{2}{|r|}{$\mathrm{CON}$} & \multicolumn{2}{|c|}{ INT } \\
\hline & Pre & Post & Pre & Post \\
\hline HbA1c, \% & $6.2 \pm 0.6$ & $6.1 \pm 0.8$ & $6.2 \pm 0.5$ & $6.1 \pm 0.8$ \\
\hline Glucose, fasting, $\mathrm{mmol} \cdot \mathrm{L}^{-1}$ & $5.9 \pm 1.1$ & $6.0 \pm 1.5$ & $6.0 \pm 1.3$ & $6.2 \pm 1.8$ \\
\hline Glucose, 2 hour, $\mathrm{mmol} \cdot \mathrm{L}^{-1}$ & $7.7 \pm 3.5$ & $8.6 \pm 5.1$ & $8.8 \pm 4.0$ & $8.9 \pm 4.8$ \\
\hline Mean glucose during 2 hour & & & & \\
\hline glucose tolerance test, $\mathrm{mmol} \cdot \mathrm{L}^{-1}$ & $10.5 \pm 2.4$ & $9.1 \pm 2.5$ & $10.5 \pm 3.1$ & $9.5 \pm 3.2$ \\
\hline Insulin, fasting, $\mathrm{pmol} \cdot \mathrm{L}^{-1}$ & $94 \pm 52$ & $108 \pm 75$ & $110 \pm 74$ & $98 \pm 54$ \\
\hline Insulin, 2 hour, $\mathrm{pmol} \cdot \mathrm{L}^{-1}$ & $634 \pm 388$ & $712 \pm 415$ & $921 \pm 654$ & $907 \pm 720$ \\
\hline C-peptide, fasting, $\mathrm{pmol} \cdot \mathrm{L}^{-1}$ & $596 \pm 253$ & $622 \pm 257$ & $659 \pm 197$ & $612 \pm 208$ \\
\hline C-peptide, 2 hour, pmol $\cdot \mathrm{L}^{-1}$ & $2486 \pm 790$ & $2508 \pm 702$ & $2995 \pm 1206$ & $2733 \pm 1080$ \\
\hline Triglycerides, fasting, $\mathrm{mmol} \cdot \mathrm{L}^{-1}$ & $1.7 \pm 1.1$ & $1.8 \pm 0.9$ & $1.4 \pm 0.5$ & $1.3 \pm 0.6$ \\
\hline $\mathrm{HDL}$ cholesterol, $\mathrm{mmol} \cdot \mathrm{L}^{-1}$ & $1.3 \pm 0.2$ & $1.3 \pm 0.3$ & $1.2 \pm 0.3$ & $1.2 \pm 0.2$ \\
\hline $\mathrm{LDL}$ cholesterol, $\mathrm{mmol} \cdot \mathrm{L}^{-1}$ & $3.5 \pm 1.1$ & $3.7 \pm 0.9$ & $3.4 \pm 1.0$ & $3.2 \pm 1.0 \#$ \\
\hline Waist circumference, $\mathrm{cm}$ & $97.8 \pm 13.8$ & $99.0 \pm 12.1$ & $96.2 \pm 6.0$ & $94.8 \pm 6.0 \$ \#$ \\
\hline Body weight, kg & $80.7 \pm 17.8$ & $81.3 \pm 17.1$ & $74.4 \pm 10.7$ & $73.7 \pm 10.4 * \#$ \\
\hline Systolic blood pressure, $\mathrm{mm} / \mathrm{Hg}$ & $121 \pm 18$ & $123 \pm 19$ & $125 \pm 17$ & $122 \pm 14$ \\
\hline Diastolic blood pressure, $\mathrm{mm} / \mathrm{Hg}$ & $80 \pm 11$ & $80 \pm 9$ & $77 \pm 10$ & $77 \pm 7$ \\
\hline
\end{tabular}

Mean values \pm SD. $\$=p<0.1$ within group. ${ }^{*}=\mathrm{p}<0.05$ within group. $\#=\mathrm{p}<0.05$ between groups for change from pre to post of the 12 week intervention. $\mathrm{n}=20$ for HbA1c, fasting glucose, 2 hour glucose, fasting insulin, fasting TG, HDL, LDL, Sys BP, Dias BP, body weight and waist circumference in both CON and INT. $\mathrm{n}=17$ for 2 hour insulin, fasting c peptide and 2 hour $\mathrm{c}$ 
peptide in CON. $\mathrm{n}=14$ for 2 hour insulin and 2 hour c peptide INT. $\mathrm{n}=15$ for fasting c-peptide in INT. 


\section{Figure captions}

Fig 1. Participant flow chart

Fig 2. Oral glucose tolerance test in relation to the activity pattern in the intervention group. Curves are blood glucose sampled every $15^{\text {th }}$ minute during pre and post oral glucose tolerance test for CON (left, $\mathrm{n}=15$ ) and INT (right, $\mathrm{n}=16$ ). The line with a walking man indicates the pattern of physical activity performed during intervention (Mean: 56 minutes duration, 1.3 times per day with start 30 minutes after a meal, $n=20)$. I.e. physical activity took place when blood glucose was expected to be elevated. 


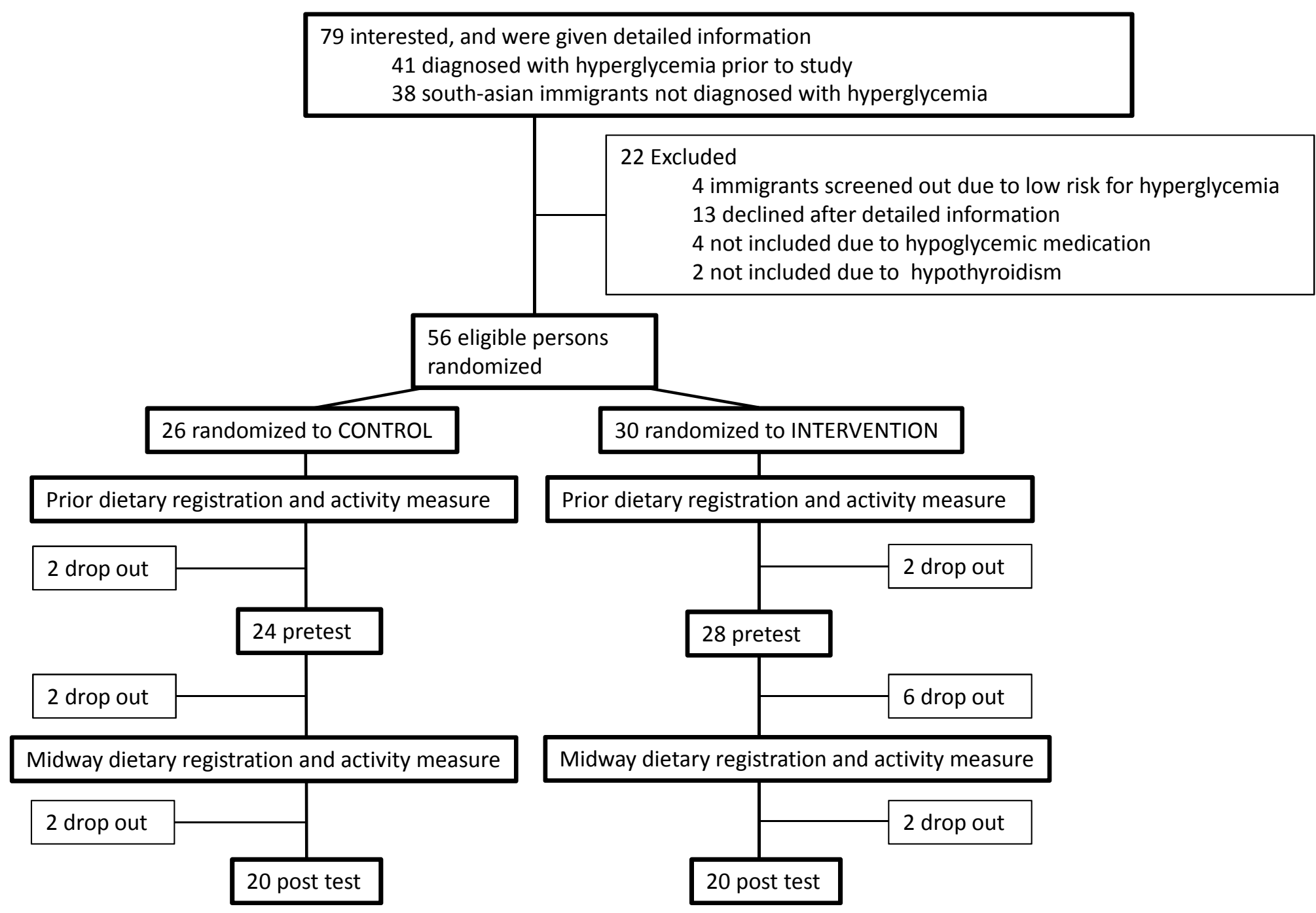



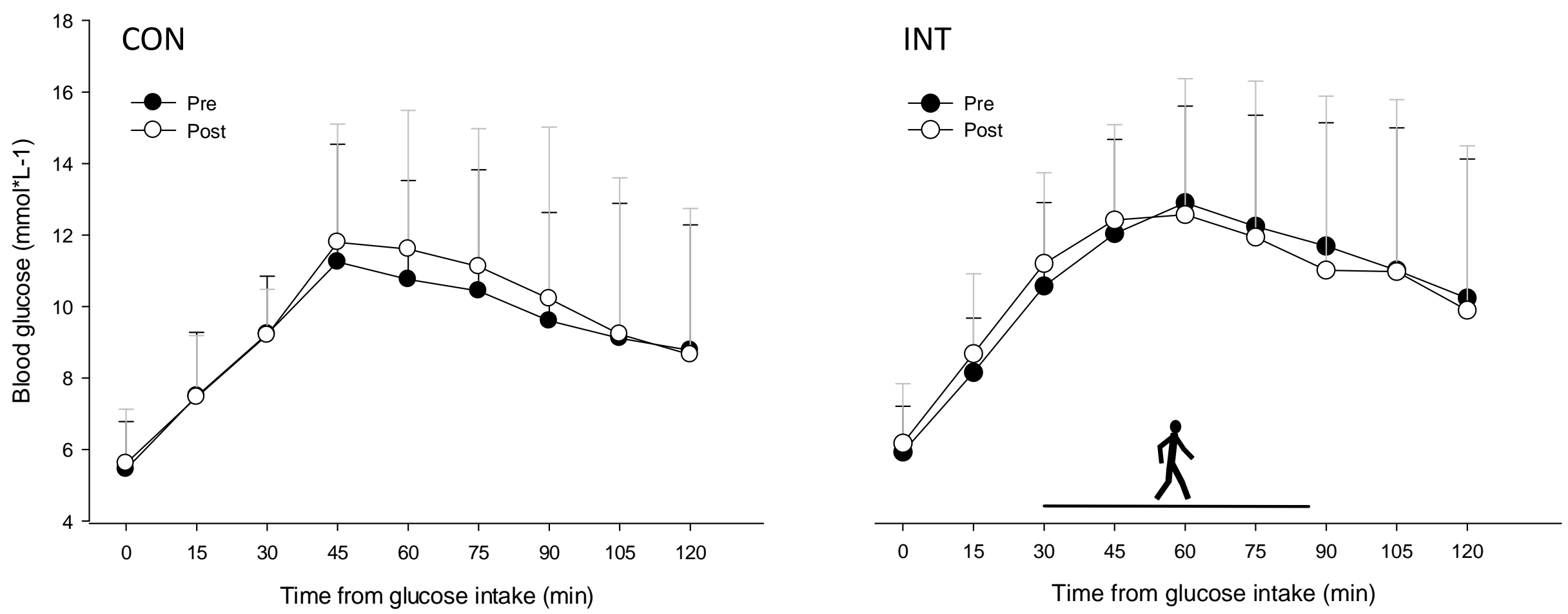